\title{
Geração dos diagramas de execução de modelos de lapidação de gemas
}

\author{
Álvaro Postal ${ }^{1}$ \\ Alexandre Lazaretti Zanatta ${ }^{1}$ \\ Juliano Tonezer da Silva ${ }^{1}$ \\ Marcos José Brusso ${ }^{1}$ \\ Léo A. Hartmann ${ }^{2}$
}

\begin{abstract}
Resumo. A lapidação é uma técnica para modelar determinados tipos de materiais. Este trabalho apresenta uma solução para geração de diagramas de execução para o processo de lapidação de gemas. Os indícios e as reflexões apresentadas neste trabalho indicam que, com o uso dos diagramas gerados, o processo de lapidação de gemas pode ser mais produtivo.
\end{abstract}

Palavras-chave: Gemas. Pedras preciosas. Diagramas de lapidação.

\begin{abstract}
Stone cutting is a technique for modeling certain kinds of materials. This paper presents a solution for the generation of performance diagrams for the gemstones cutting process. The evidences indicate that with the use of these generated diagrams the stone cutting process can be more productive.
\end{abstract}

Keywords: Gems. Precious stones. Stone cutting diagrams.

\section{Introdução}

O beneficiamento das gemas a partir do seu estado bruto é realizado pelo processo de lapidação, com o objetivo de aperfeiçoar suas qualidades ópticas, aumentar seu brilho, definir suas formas, realçar suas cores e belezas naturais. A lapidação é responsável, em grande parte, pela valorização da gema depois de lapidada, a qual terá um aumento considerável no seu valor. Por outro lado, a lapidação com facetas desencontradas (desalinhadas), polimento irregular e proporções incorretas pode desvalorizar a gema, por provocar perda de luminosidade e beleza.

No Brasil, a lapidação, ao longo das últimas décadas, perdeu muito em competitividade para as empresas estrangeiras, pela qualidade inferior, do processo, que ainda conserva a tradição do processo manual de lapidação de gemas, com técnicas do período colonial [2].

Por isso, o objetivo deste trabalho é gerar o diagrama de execução que auxilia no processo de lapidação, ou seja, oferece ao lapidador os parâmetros de como ficará seu trabalho, bem como as etapas que devem ser seguidas para que o resultado fique satisfatório. É importante destacar que este trabalho é parte integrante do projeto 3D-Gemas ${ }^{3}$, que possui como objetivo desenvolver uma solução tecnológica (software) para identificar qual é o melhor modelo de lapidação para uma determinada gema. Após digitalizar a gema e processar as informações, é disponibilizada ao usuário uma lista de modelos de lapidação com seus respectivos aproveitamentos ao escolher o modelo de lapidação.

O presente trabalho está organizado da seguinte forma: a seção 2 apresenta alguns conceitos sobre gemas, seus tipos naturais, orgânicas, sintéticas e artificiais e suas características, além de conceitos iniciais de lapidação

\footnotetext{
${ }^{1}$ Universidade de Passo Fundo (UPF), Ciência da Computação, Caixa Postal 611, Passo Fundo, RS, Brasil.

alvaropostal@bol.com.br, \{zanatta, tonezer, brusso\}@upf.br

${ }^{2}$ Universidade Federal do Rio Grande do Sul (UFRGS), Instituto de Geociências, Avenida Bento Gonçalves, 9500, Bloco I, Prédio 43113, Campus do Vale, Agronomia, CEP 91509-950 - Porto Alegre, RS, Brasil.

leo.hartmanneufrgs.br

${ }^{3}$ O 3D-Gemas é um projeto em desenvolvimento no Centro Tecnológico de Pedras, Gemas e Joias do RS, localizado na cidade de Soledade no estado do Rio Grande do Sul, com o objetivo de desenvolver uma solução tecnológica para auxiliar a lapidação, visando encontrar o melhor aproveitamento de um modelo de lapidação a uma gema específica.
}

doi: $10.5335 /$ rbca. 2010.007 
e seus processos: manual, automatizado e mecanizado; a seção 3 detalha os diagramas gerados, explicando o seu funcionamento e todas as etapas do seu desenvolvimento; por fim, a seção 4 apresenta as conclusões e os trabalhos futuros.

\section{Gemas, lapidação e diagrama}

Esta seção define conceitos sobre as gemas, os processos de lapidação e os diagramas. Essas informações serão utilizadas para a geração do Diagrama de Execução.

\subsection{Gemas}

Gemas são cristais naturais ou sintéticos, às vezes com aspecto áspero ou irregular, transformados pelo ser humano em objetos lapidados e atrativos [6]. A definição de gemas tem variado no decorrer dos anos. Inicialmente, eram definidas como pedras preciosas ou semipreciosas, mas atualmente a definição de semipreciosa não é mais utilizada pelo público relacionado com gemas.

De acordo com [7], existem diferentes tipos de materiais gemológicos. A maioria das gemas é formada principalmente por minerais e rochas. Entretanto, as gemas podem ser divididas em quatro grupos, levando em consideração sua origem, que pode ser natural, orgânica, sintética ou artificial. As gemas naturais são materiais produzidos pela natureza sem a intervenção do homem, formadas em rochas e encontradas tanto em depósitos primários, nas próprias rochas, como em depósitos secundários, no fundo de rios, nos sedimentos ali depositados [6].

As gemas orgânicas são formadas de restos de plantas ou animais que se cristalizaram ou petrificaram por ação da natureza. Como exemplos: o âmbar, que é a resina de árvore fossilizada; o marfim, que pode ser de ossos ou dentes provenientes de animais vivos ou fósseis de milhares de anos; o azeviche de madeira fossilizada; o coral formado a partir de esqueleto de pequenos animais e, finalmente, a pérola, que é proveniente de ostras de água salgada ou doce.

As gemas sintéticas são produzidas pelo homem, visando obter características como cor, brilho ${ }^{4} \mathrm{e}$ transparência iguais às gemas naturais. Por exemplo, o rubi sintético assemelha-se ao rubi natural, tanto na composição química, como na estrutura cristalina e nas propriedades físicas, porém o fato de ter sido criado em laboratório o impede que seja classificado como gema natural, e sim como gema sintética.

As gemas artificiais foram inventadas pelo ser humano visando imitar as características visuais de uma gema natural. As características da composição química e estrutura cristalina são completamente diferentes. Por exemplo, a zircônia cúbica, visualmente, assemelha-se ao diamante, porém sua composição química é o óxido de zircônio $\left(\mathrm{ZrO}_{2}\right)$, bem diferente do carbono $(\mathrm{C})$, que é a composição do diamante.

Todas as gemas possuem características que dependem da sua estrutura atômica e de suas ligações químicas internas. Essas características são denominadas "propriedades físicas" e são utilizadas pelos gemólogos e lapidários para identificar e classificar as gemas. O conhecimento das principais características ou propriedades das gemas é de extrema importância para o lapidador, pois apenas com o devido conhecimento se pode lapidar, usar e cuidar corretamente de uma gema [7].

\subsection{Lapidação}

A lapidação é o processo de beneficiamento das gemas a partir do seu estado bruto com o objetivo de aperfeiçoar suas qualidades ópticas, aumentar seu brilho, definir suas formas, realçar suas cores e beleza natural. $\mathrm{O}$ beneficiamento de uma gema pode ser realizado pelo processo manual, mecanizado ou automatizado de lapidação.

O processo manual de lapidação de gemas é relativamente complexo, pois depende amplamente da capacidade operacional do lapidário. Esse processo é dividido em quatro etapas: a) corte ou serragem: nessa etapa o lapidário faz cortes na gema utilizando uma serra diamantada para remover as impurezas, deixando

\footnotetext{
${ }^{4}$ O brilho é uma das propriedades ópticas das gemas, assim como a cor, a refração e a transparência. Toda a propriedade óptica depende da luz. "A estrutura cristalina individual de uma gema interage com a luz de forma exclusiva e determina as propriedades ópticas de cada tipo de gema”. [3].
} 
apenas a área que pode ser aproveitada para a lapidação, eliminando os defeitos; b) calibragem: consiste em desgastar a gema para dar uma forma preliminar (pré-forma) e aproximada da forma final que ela deverá assumir; c) facetamento: consiste em dar à gema as facetas que definirão sua forma final, é a etapa na qual são criadas as facetas na gema; d) polimento: consiste em dar brilho às facetas da gema com um disco de polir. As informações sobre o processo manual de lapidação foram obtidas principalmente no Manual delLapidação de gemas - processo manual [1].

Além do processo manual de lapidação existem outras técnicas de processo de lapidação que podem aperfeiçoar tanto a qualidade da gema lapidada como o processo de criação da mesma. O processo mecanizado e o automatizado de lapidação possibilitam uma exatidão nos seus passos, pois utilizam mecanismos de medição e corte milimétrico da gema.

O processo mecanizado de lapidação de gemas difere do processo manual pelo fato de possuir um braço mecânico com regulagens milimétricas, auxiliando o lapidador nos processos de calibragem, facetamento e polimento e proporcionando, com isso, um melhor acabamento em um menor tempo, conforme destaca [2]. O processo manual ou o mecanizado de lapidação de gemas seguem um modelo de lapidação, o qual se resume a um diagrama de execução, com o qual o lapidador transforma sua gema bruta em uma gema lapidada, conforme o modelo descrito no diagrama. O projeto 3D-Gemas desenvolve uma ferramenta (software) que oferecerá suporte aos dois processos de lapidação.

O processo automatizado de lapidação de gemas envolve equipamentos eletrônicos e mecânicos, utilizando um software específico para executar os passos da lapidação. Nesse processo, a única intervenção humana, não havendo erros ou defeitos no equipamento, ocorre para colocar a gema no equipamento, inverter a posição após lapidar um lado, o lapidador deve inverter a gema para lapidar o outro lado, e removê-la do equipamento.

\subsection{Diagramas}

Diagrama é uma representação visual estruturada e simplificada de um determinado conceito. De acordo com [4], um modelo de lapidação pode ser definido por meio de um diagrama de execução, no qual são descritos todos os parâmetros geométricos, relações entre dimensões e ângulos necessários para o corte de cada faceta, assim como o número de facetas.

O diagrama de execução tem como objetivo mostrar ao lapidador os parâmetros de como ficará seu trabalho final, assim como os passos a serem seguidos para que o resultado fique satisfatório. Existem diferentes diagramas de execução no mercado, cada um com suas particularidades tanto na parte ilustrativa (imagens e figuras) como na parte textual (informações), mas todos com o mesmo objetivo, de informar e orientar o executor (lapidador) no seu trabalho. Assim, é importante para o lapidador que o diagrama gerado seja compreensível, legível e, principalmente, confiável ao detalhar as informações, pois um erro de valor no diagrama pode invalidar o projeto.

\section{Diagrama Gerado}

Esta seção tem como objetivo descrever o desenvolvimento do Diagrama de Execução. Inicialmente, foram realizados estudos de alguns diagramas existentes no mercado nacional e internacional, entre os quais o diagrama do Senai de Soledade/RS, da empresa Lapidart - Belo Horizonte/MG, da empresa Lemon TechnoMist (software DiaSoft) - Índia e da empresa GemSoft Enterprises (software GemCad) - EUA. O foco desse estudo foi compreender o funcionamento desses diagramas, que tipo de informações são exibidas, como eram organizadas as informações e o posicionamento das imagens e tabelas.

Após, foram realizadas visitas em empresas do setor de lapidação de gemas em Soledade-RS para verificar o tipo de processo de lapidação que essas empresas estavam usando: se o manual, o mecanizado, o automatizado, ou uma combinação desses processos. Verificou-se que a maioria das empresas utilizava o processo manual de lapidação. É importante observar que o processo automatizado não foi constatado em nenhuma das empresas visitadas. Em seguida, foram levantados os requisitos que deveriam constar no diagrama, visando aos interesses e às necessidades dessas empresas.

Para o processo manual de lapidação os requisitos levantados foram: a) a exibição das imagens do modelo de lapidação em diferentes visões, frontal, superior, lateral, inferior e perspectiva; b) a utilização de 
identificadores de medidas do modelo, mostrando as proporções da mesa, da coroa, da cintura e do pavilhão para o modelo e para a pré-forma do modelo; c) a exibição das imagens da pré-forma do modelo com a gema bruta para identificar por onde iniciar a lapidação; d) divulgar qual o nome do modelo, o número de facetas, o aproveitamento do modelo e o peso estimado do modelo; e) mostrar os ângulos de corte da coroa e do pavilhão da pré-forma do modelo.

Já para o processo mecanizado de lapidação foram acrescentados os seguintes requisitos do processo manual: a) divulgar o valor do índex ${ }^{5}$ a ser utilizado; b) descrever os ângulos de corte para cada faceta; c) identificar o valor do índex para o corte de cada faceta; d) representar nas imagens do modelo a posição de cada faceta.

Na primeira visita realizada às empresas participantes do projeto apresentou-se um protótipo do Diagrama de Execução que será gerado pelo software. A apresentação do protótipo teve como objetivo que as empresas participantes pudessem analisá-lo e criticá-lo para ajustes e aperfeiçoamento. Com os dados advindos da primeira visita, a equipe do projeto reuniu-se e apresentou uma nova versão do diagrama que foi apresentado e aprovado pelas empresas participantes na segunda entrevista.

Superada a fase do levantamento e da análise dos requisitos do diagrama, surgiu a necessidade de se projetarem as imagens do modelo e da pré-forma do modelo. Buscou-se o Sistema de Projeções Ortogonais Pelo $1^{\circ}$ Diedro, por ser o padrão mais utilizado no Brasil. Um sistema de projeções ortogonais é a forma de representar um objeto tridimensional por meio de desenhos bidimensionais. Essa representação é denominada Geometria Descritiva [5].

As tecnologias utilizadas para o desenvolvimento do diagrama foram: sistema operacional Linux (kubuntu 8.04); a ferramenta de desenvolvimento QT4; o ambiente de desenvolvimento QDevelop para QT4; a linguagem de programação $\mathrm{C}++$; a biblioteca gráfica OpenGL; a linguagem de marcação de dados XML e a utilização de arquivos com extensões PNG para leitura e PDF para leitura e gravação. A utilização das extensões PNG e PDF foi exclusivamente adotada para serem utilizadas pelo diagrama de execução. Para a escolha do formato PNG foram comparados os arquivos dos tipos JPEG, BMP, TIF, GIF e PNG a partir da geração de imagens (tamanho 2482 x 3507 pixels e qualidade $96 \mathrm{dpi}$ ) em formatos citados. Pode-se observar que os formatos PNG e GIP foram os que tiveram o menor tamanho em bytes e, ao se aplicar zoom de 20x, percebeu-se que os formatos PNG, BMP e TIF apresentaram imagens mais nítidas em relação às outras. A extensão PDF foi utilizada em razão da sua portabilidade.

A Figura 1 representa o diagrama geral do funcionamento do software gerado pelo projeto 3D-Gemas.

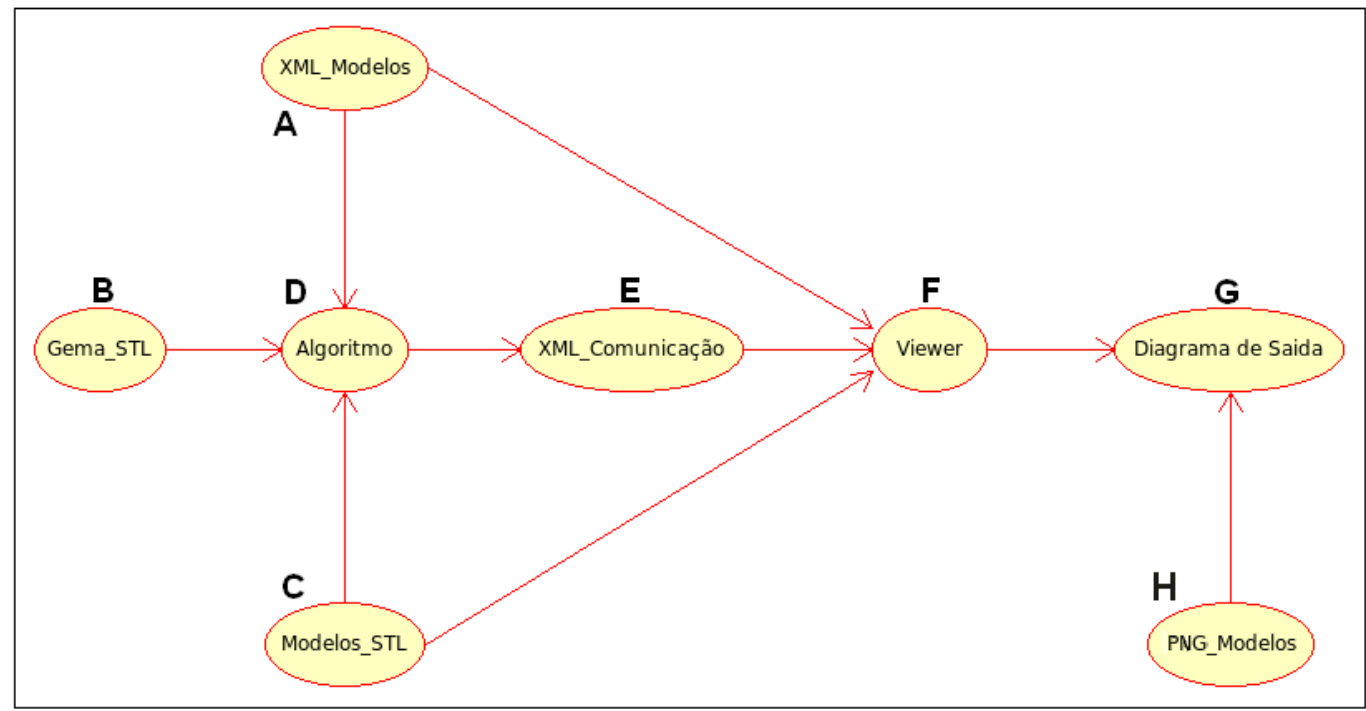

Fonte: Primária.

Figura 1. Diagrama Geral

\footnotetext{
5 Índex é a indicação do número de divisões utilizado para indicar a posição de corte das facetas da gema.
} 
O módulo "A" (XML_Modelos) da Figura 1 é um arquivo XML que contém dados estáticos sobre o modelo de lapidação específico, isto é, existe um XML para cada modelo de lapidação, como, por exemplo, o Oval8.xml. Os dados estáticos do arquivo XML estão divididos em dois grupos, a seguir descritos:

a. Grupo 1: contém os seguintes dados que serão utilizadas pelo módulo "F" (Visualizador 3D Gemas): nome do modelo (Redondo8); valor do índex (96); valor do índice de refração (RI) (1,54); o número de facetas do modelo (57); o número de facetas na cintura do modelo (0); o ângulo de corte da coroa na pré-forma $\left(36^{\circ}\right)$; o ângulo de corte do pavilhão na pré-forma $\left(45^{\circ}\right)$; uma sequência de cortes de facetas (06-18-30-42-54-66-78-90), com seu ângulo $\left(41,5^{\circ}\right)$ e um indicador de posição (P2), aqui são informados todos os cortes de cada faceta do modelo.

b. Grupo 2: contém os seguintes dados que serão utilizadas pelo módulo " $\mathrm{D}$ " (Algoritmo): valor de L1 (10), sendo esse valor uma referência utilizada para gerar todos os demais valores aqui descritos; valor de L2 (100\%), todas as porcentagens são referentes ao valor de L1; valor M1 (59,58\%); valor de M2 (59,58\%); valor da coroa (11,27\%); valor da cintura (2\%); valor do pavilhão $(45,10 \%)$; valor total $(58,37 \%)$; valor da coroa da pré-forma $(11,70 \%)$; valor do pavilhão da pré-forma $(45,12 \%)$.

O módulo "B" (Gema_STL) da Figura 1 é um arquivo contendo uma nuvem ${ }^{6}$ de pontos referente à gema digitalizada, a qual é utilizada no módulo " $\mathrm{D}$ " (Algoritmo) para ser processada. No formato padrão o nome do arquivo será o primeiro nome do proprietário ou da empresa dona da gema, juntamente com um número sequencial.

O módulo "C" (Modelos_STL) da Figura 1 também é uma nuvem de pontos, porém refere-se aos modelos de lapidação. Estes arquivos serão utilizados no módulo "D" (Algoritmo) como base de cálculo e no módulo "F" (Visualizador 3D Gemas) para ser exibido na interface.

O módulo "D" (Algoritmo) da Figura 1 é o centro de processamento do software que, após receber os dados dos módulos "A", "B" e "C", processa e envia as informações para o módulo E (XML_Comunicação).

O módulo "E" (XML_Comunicação) da Figura 1 é um arquivo XML único para cada projeto. As informações neles contidas são advindas do módulo "D" (Algoritmo) e são repassadas para o módulo "F" (Visualizador 3D Gemas). As informações deste XML são: nome do proprietário; identificação da gema (ametista, citrino ou ágata); data do processamento (dia/mês/ano); a nuvem de pontos da gema (obtida no módulo "B" (Gema_STL)); aqui estão as informações de cada modelo de lapidação calculado (exemplo: Redondo8), com o peso (50ct); aproveitamento (37\%); valor da escala, para poder desenhar na interface; os valores de centramento, para posicionar a gema e o modelo na interface; valor da coroa $(2,3 \mathrm{~mm})$; valor da cintura $(0,4 \mathrm{~mm})$; valor do pavilhão $(9 \mathrm{~mm})$; valor altura total $(11,7 \mathrm{~mm})$; valor mesa M1 $(11,9 \mathrm{~mm})$; valor da mesa M2 (11,9 mm); valor do lado L1 $(20 \mathrm{~mm})$; valor do lado L2 $(20 \mathrm{~mm})$; valor do pavilhão da pré-forma (9 $\mathrm{mm})$; valor da coroa da pré-forma $(2,3 \mathrm{~mm})$; valor da altura total da pré-forma $(11,7 \mathrm{~mm})$.

O módulo "F" (Visualizador 3D Gemas) da Figura 1 representa a interface com o usuário que mostra os resultados de todo o processamento. Podem-se escolher os modelos de lapidação e visualizá-los dentro da gema digitalizada, mostrando, assim, o seu aproveitamento e demais detalhes que ajudarão na escolha do melhor ${ }^{7}$ projeto para se lapidar. O Visualizador 3D Gemas acessa as informações contidas nos módulos "A", "C" e "E", trazendo-as para a memória RAM do computador e mostrando-as na interface para o usuário.

O módulo "G" (Diagrama de Saída) da Figura 1 é o resultado do projeto de lapidação na forma impressa ou virtualmente (PDF). O diagrama possui uma interação com a interface, pois existem informações que são utilizadas na geração do diagrama, como a escolha do modelo de lapidação e as imagens da pré-forma do modelo, que são mostradas no Visualizador 3D Gemas. O Diagrama de Saída é dividido em dois diagramas, o Diagrama de Execução e o Diagrama da Pré-Forma

O módulo "H" (PNG_Modelos) da Figura 1 é um repositório de imagens dos modelos de lapidação que serão exibidas no diagrama, onde cada modelo de lapidação possui uma imagem específica no formato PNG, sendo utilizado pelo módulo "G" no momento da geração do diagrama.

\footnotetext{
${ }^{6}$ Nuvem de pontos se refere ao conteúdo do arquivo STL, sendo um conjunto de pontos e suas coordenadas responsáveis por formar a malha do objeto tridimensional.

${ }^{7}$ Melhor refere-se à escolha do modelo com o maior aproveitamento ou à escolha do modelo que atende às necessidades do lapidador (exemplo: preciso de duas gemas do formato Oval8 para fazer um par de brincos).
} 
O Visualizador 3D Gemas, como pode ser observado na Figura 2, possui na barra de ferramentas e botões para auxiliar a navegação do usuário, entre os quais está o gerador de diagrama destacado na Figura 2. Ao abrir um projeto de lapidação são lidas as informações do XML_Modelos, do XML_Comunicação e do Modelos_STL, as quais são armazenadas na memória RAM; após, são mostrados na coluna da direita todos os modelos de lapidação calculados pelo algoritmo. Por exemplo, o modelo selecionado é o Oval8, indicado pela letra "B" da Figura 2 no mesmo momento em que o botão "Gerar Diagrama" é liberado para uso. Quando pressionado o botão "Gerar Diagrama", dá-se início aos procedimentos de geração do diagrama em "void MainWindowImpl::on_actionGeraDiagrama_activated()".

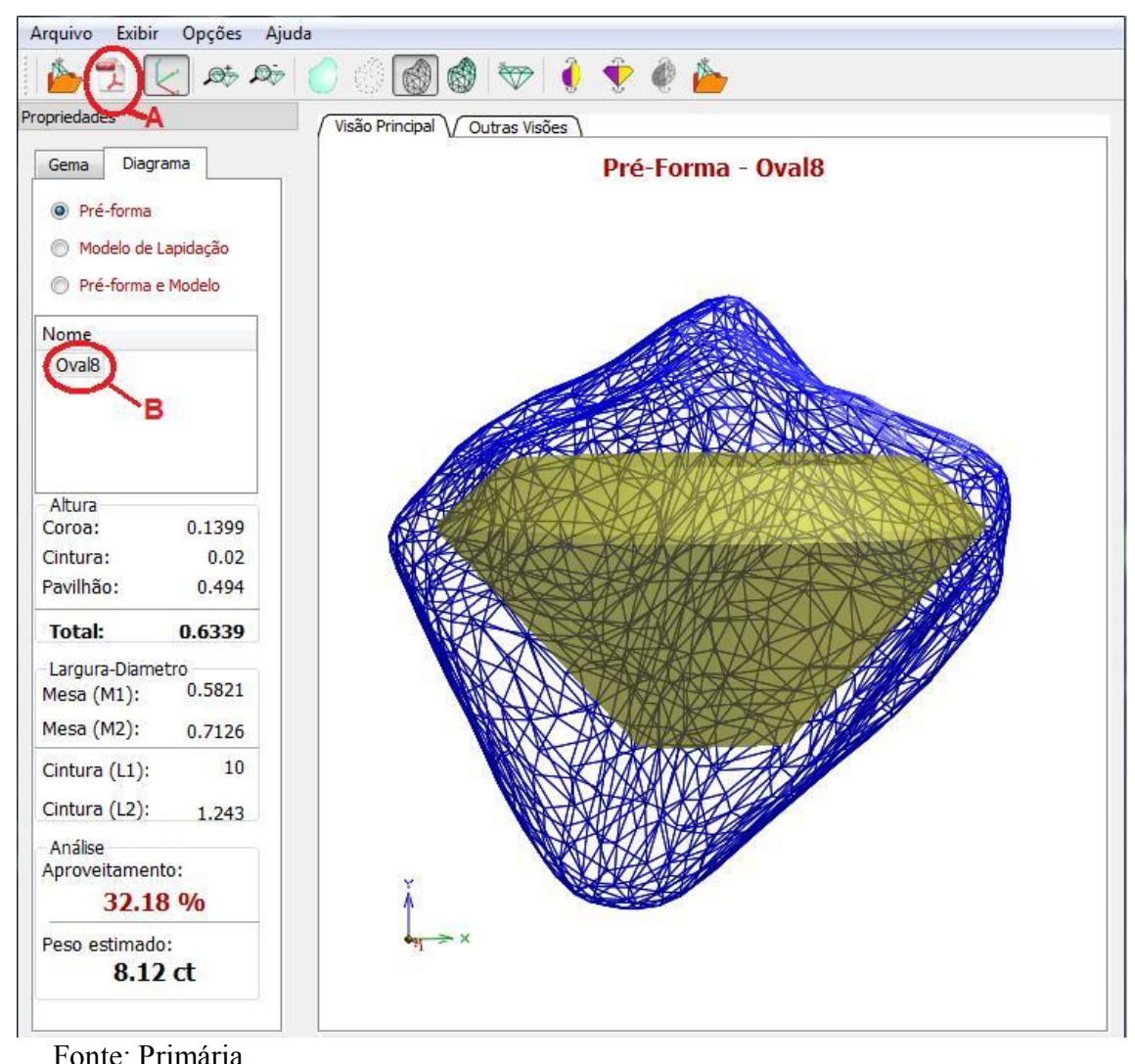

Figura 2. Visualizador 3D Gemas

O primeiro procedimento para a geração do diagrama é identificar qual o modelo de lapidação foi selecionado pelo usuário. Neste caso, foi o Oval8, indicado pela letra "B" da Figura 2; com essa informação o passo seguinte é carregar o esqueleto do diagrama, ou seja, as linhas de divisões, o logo do 3D-Gemas e as imagens do modelo no repositório de imagens PNG_Modelos e da pré-forma do modelo, capturadas a partir do Visualizador 3D Gemas, utilizando o comando "QPixmap", para carregar as imagens; o comando "QRectF", para indicar a posição da imagem no diagrama, e o comando "painter.drawPixmap", sendo painter do tipo QPainter, para desenhar. Após, são obtidas as informações de texto estáticas, como, por exemplo, o rodapé, os títulos das colunas (projeto de lapidação, proporções, pavilhão, coroa, pré-forma, proporções pré-forma), identificadores de dados e extensões de dados $\left({ }^{\circ}, \%, \mathrm{~mm}\right.$, ct). Posteriormente, são carregadas as informações referentes ao modelo e a pré-forma do modelo pela função "painter.drawText()", que mostra os dados em uma posição prédefinida, tornando-se necessário indicar coordenadas para cada imagem ou texto que será desenhado ou escrito no diagrama.

Com o diagrama pronto para ser mostrado ao usuário, a função "printer.setOutputFormat( QPrinter::PdfFormat)" define o formato do arquivo que será salvo (neste caso, o formato PDF) e a função "printer.setOutputFileName(/projetos/Oval8.PDF)", que salva o arquivo num local predeterminado com o nome Oval8.PDF. Em seguida, a função "ShellExecute()" abre o arquivo Oval8.PDF usando o editor de PDF padrão que o usuário possua e a função "process.startDetached()", "process.waitForStarted()" (sendo process do tipo QProcess), a qual mantém o arquivo PDF aberto para que possa ser impresso. 
Em virtude do considerável tamanho das imagens, em pixel, e do número de informações descritas no diagrama, dividiu-se o diagrama em duas partes utilizando a função "printer.newPage()" para criar uma nova página no arquivo PDF. A primeira página foi chamada de Diagrama de Execução, que contém os dados e imagens do modelo de lapidação, e a segunda página, o Diagrama da Pré-Forma, com os dados e imagens da pré-forma do modelo.

\subsection{Diagrama de Saída}

O Diagrama de Saída é o resultado do projeto de lapidação e gera o Diagrama de Execução e o Diagrama da Pré-Forma. A seguir proceder-se a um detalhamento do funcionamento do Diagrama de Saída.

A letra "A" da Figura 3 indica que existe uma função que envia o número de facetas do modelo, o número de facetas da cintura do modelo, o valor do índex, o valor do R.I., os ângulos e cortes das facetas do pavilhão e da coroa do XML Modelos para o Diagrama de Execução. A letra "B" da Figura 3 indica que existe uma função que envia do XML__Modelos para o Diagrama da Pré-Forma o ângulo da pré-forma do pavilhão e o ângulo da pré-forma da coroa. A letra "C" da Figura 3 indica que são encaminhados do XML_Comunicação para o Diagrama da Pré-Forma os dados do nome do projeto, da data do projeto e das proporções do modelo, como altura $(H)$, coroa $(C)$, cintura(R), pavilhão(P), lado(L1) e lado(L2).

A letra "D" da Figura 3 indica que são enviados do XML_Comunicação para o Diagrama de Execução os dados do nome do projeto, da data do projeto, do aproveitamento, do peso estimado e das proporções do modelo, como altura(H), coroa(C), cintura(R), pavilhão(P), lado(L1), mesa(M1), lado(L2) e mesa(M2). A letra "E" da Figura 3 mostra que informação do modelo do projeto selecionado pelo usuário do Visualizador 3D Gemas é repassada para o Diagrama de Execução. A letra "F" da Figura 3 indica que existe um envio da informação do modelo do projeto selecionado pelo usuário e as imagens da pré-forma do modelo do Visualizador 3D Gemas para o Diagrama da Pré-Forma. A letra "G" da Figura 3 indica que são armazenadas as imagens das linhas de divisão e bordas ou o esqueleto do diagrama e do logo do 3D-Gemas do repositório de imagens PNG_Modelos para o Diagrama da Pré-Forma.

Finalmente, a letra "H" da Figura 3 indica que são armazenados as imagens do modelo de lapidação, das linhas de divisão e bordas e o logo do 3D-Gemas do repositório de imagens PNG_Modelos para o Diagrama de Execução.

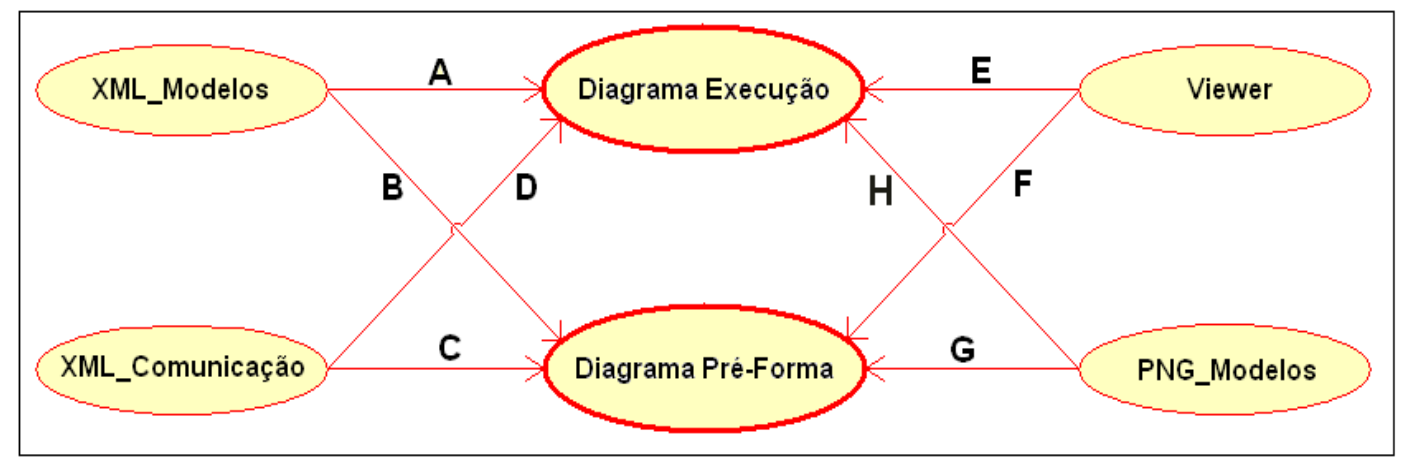

Fonte: Primária.

Figura 3. Diagrama de Saída

Esta subseção descreveu a trajetória dos dados necessários para a geração do Diagrama de Execução e do Diagrama da Pré-Forma.

\subsection{Diagrama de Execução}

O primeiro diagrama gerado denomina-se de Diagrama de Execução e pode ser observado na Figura 4. A imagem do modelo, neste caso o modelo Oval8, com o logo do 3D-Gemas e as cinco visões (frontal, superior, lateral, inferior e perspectiva) definidas no levantamento de requisitos, podem ser observadas na parte superior da Figura 4. As imagens do modelo estão acompanhadas com identificadores de medidas e de posição, indicando 
Altura (H), Coroa (G), Cintura (R), Pavilhão (P), Lado (L1), Lado (L2), Mesa (M1), Mesa (M2), indicação de posição do índex $(<96>, 24,48,72)$, indicação da posição de corte das facetas da coroa $(C 1, C 2, C 3$ e C4) e posição de corte das facetas do pavilhão (P1, P2). Cada indicador é completado com os respectivos valores descritos nas imagens (B) e (C) da Figura 4.

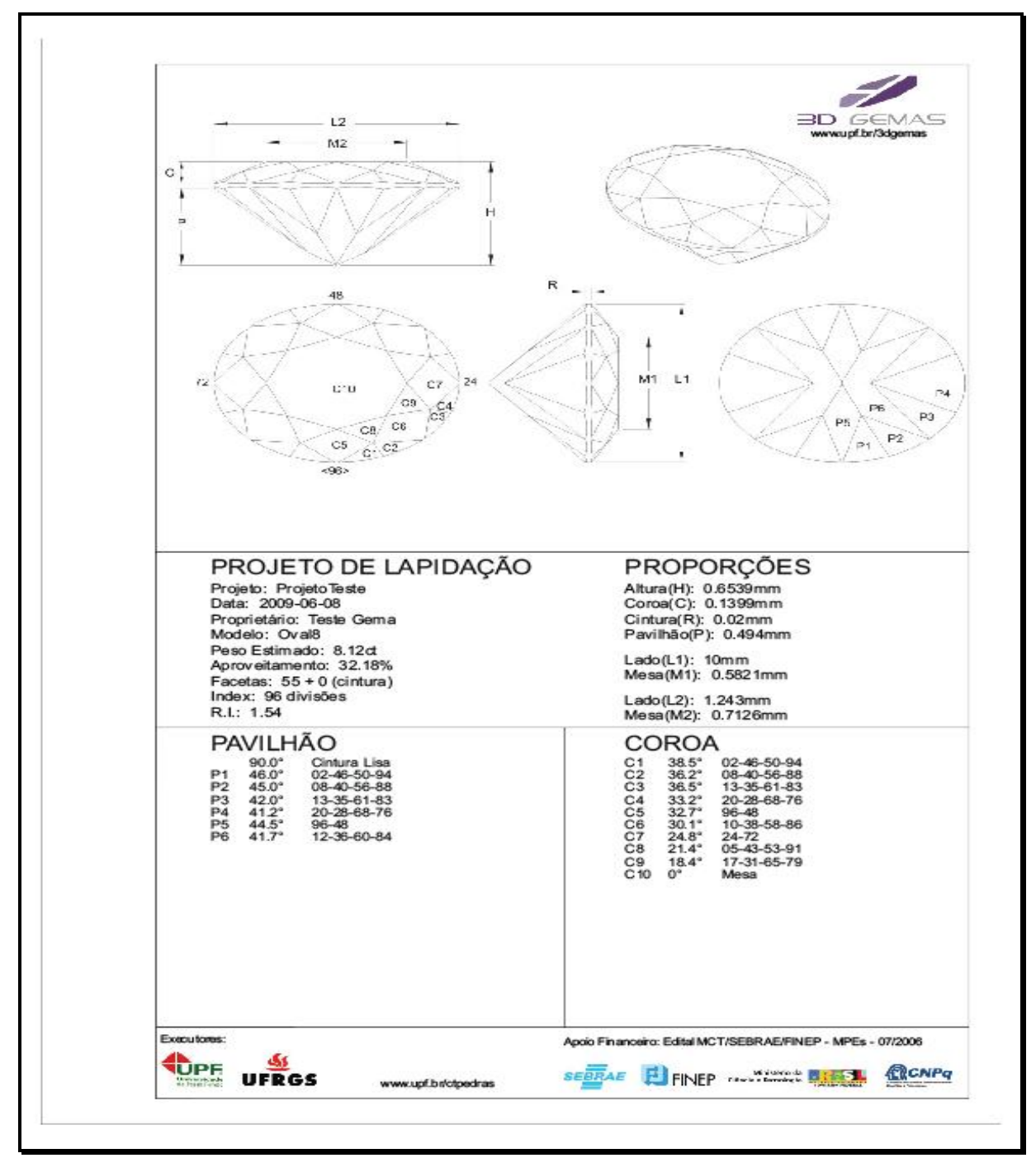

Fonte: Primária.

Figura 4. Diagrama de Execução

Na parte central do diagrama da Figura 4 situam-se informações como nome do projeto, data da criação do projeto, nome do modelo de lapidação, o peso estimado do modelo de lapidação, o aproveitamento do modelo em relação à gema bruta, o número de facetas do modelo, o valor do índex (utilizado no processo mecanizado de lapidação) e o índice de refração, utilizado para calcular o ângulo do raio de luz no interior da gema, que está relacionado com o brilho que a gema lapidada reflete.

Na parte inferior do diagrama da Figura 4 encontram-se os dados necessários para o corte de cada faceta da gema, indicando o ângulo de corte e a posição de cada faceta. Por fim, apresentam-se no rodapé do diagrama dados referentes ao Centro Tecnológico de Pedras, Gemas e Joias do RS e do Projeto 3D-Gemas. 


\subsection{Diagrama da Pré-Forma}

A segunda parte do diagrama gerado pelo presente trabalho denomina-se de "Diagrama da Pré-Forma" e tem como função orientar o lapidador nos primeiros passos da lapidação, indicando qual o posicionamento correto para iniciar o primeiro corte na gema. O Diagrama da Pré-Forma pode ser observado na Figura 5.

Na parte superior do Diagrama da Pré-Forma da Figura 5 encontra-se a imagem da pré-forma do modelo posicionado internamente na gema digitalizada, mostrando, como o algoritmo posicionou o modelo para se obter o aproveitamento descrito no Diagrama de Execução.

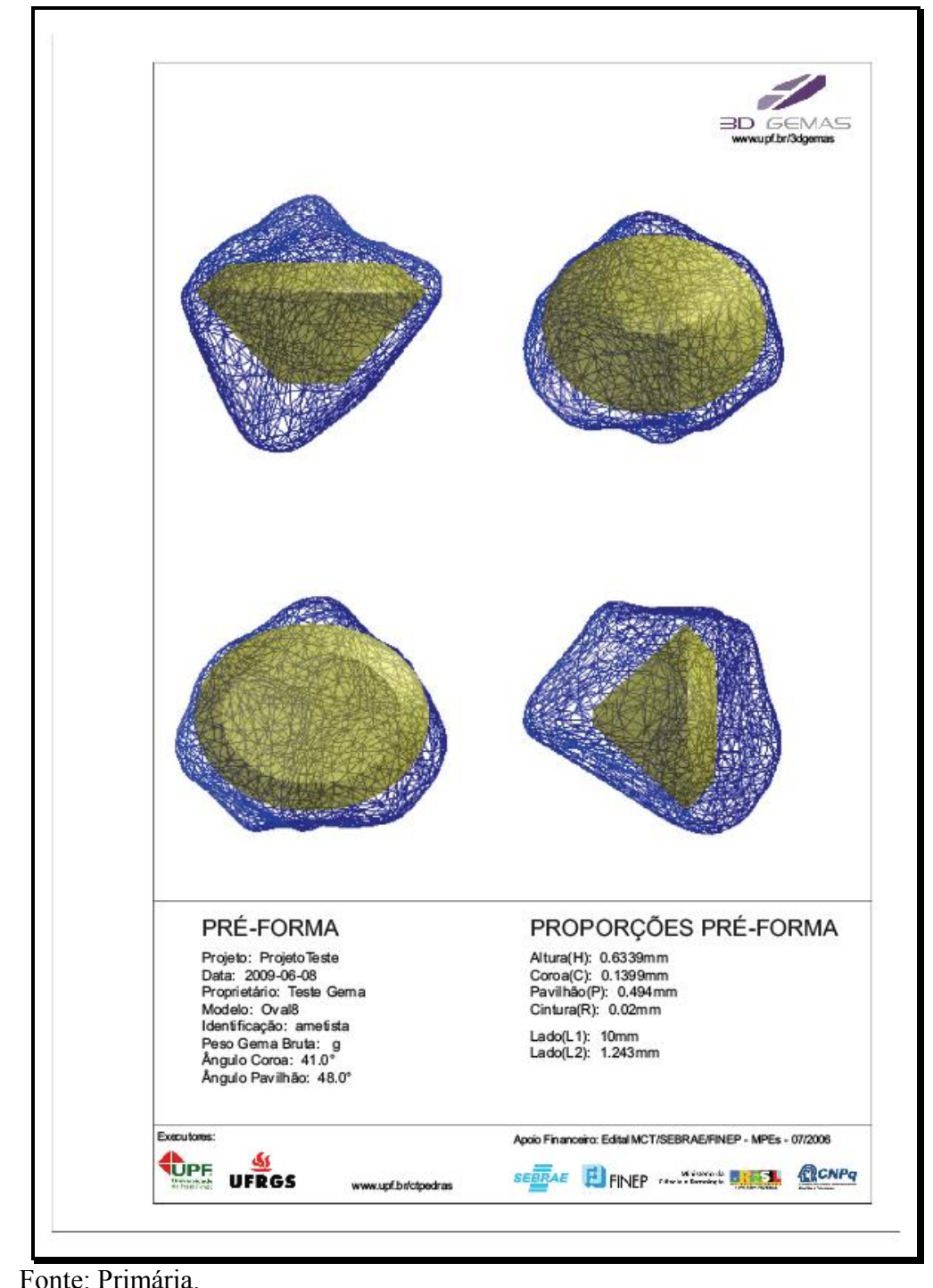

Figura 5. Diagrama da Pré-Forma

A parte inferior do Diagrama de Pré-Forma da Figura 5 contém informações sobre o nome do projeto de lapidação, a data de criação do projeto, o nome do modelo de lapidação, as informações do rodapé e o logotipo. As demais informações são referentes à pré-forma do modelo, como o ângulo de corte da coroa e do pavilhão, Altura(H), Coroa(G), Cintura(R), Pavilhão(P), Lado(L1) e Lado(L2).

O principal objetivo do Diagrama da Pré-Forma é fornecer a gema bruta uma forma semelhante ao modelo desejado e, a partir disso, ser utilizada no Diagrama de Execução. Dependendo do processo de lapidação mecanizado, da superfície da gema e da experiência do lapidados, pode não ser necessária a etapa da préformação da gemas. 
Para o peso estimado e o índice de refração (RI) a precisão dos dados utilizados no Diagrama de Execução e no Diagrama da Pré-Forma foi de duas casas decimais, levando-se em consideração tanto o processo manual como o processo mecanizado de lapidação e suas limitações ${ }^{8}$. Para as medidas das proporções da gema, das proporções da pré-forma da gema, do aproveitamento e de todas as medidas de ângulos, a precisão foi de uma casa decimal. Para os demais dados foram utilizados números inteiros. O critério para os arredondamentos foi: igual ou maior que cinco $\left(\mathrm{n}^{\circ}>=5\right)$, arredonda para cima (exemplo: aproveitamento 37,58\%, arredondando fica igual a $37,6 \%)$; se menor que cinco $\left(\mathrm{n}^{\circ}<5\right)$, arredonda para baixo.

\section{Conclusões e trabalhos futuros}

Este trabalho introduziu conceitos de gemas, tipos de lapidação e uma definição de diagrama. Também apresentou o desenvolvimento de um diagrama de execução para o processo de lapidação de gemas do projeto 3D-Gemas. A importância do diagrama de execução está vinculada diretamente ao aprimoramento da lapidação das gemas, aumentando, assim, a competitividade das empresas por produzirem uma gema com qualidade e por conseguirem um ganho no aproveitamento da matéria-prima da gema bruta. $\mathrm{O}$ diagrama pode ser utilizado por lapidadores que usam o processo manual de lapidação e pelos que usam o processo mecanizado de lapidação.

Atualmente, como estão no repositório apenas os modelos de lapidação Redondo8, Redondo10, Oval8 e Oval10, espera-se futuramente acrescentar em XML_Modelos, STL_Modelos e PNG_Modelos novos modelos ao repositório. Por fim, espera-se validar o diagrama de execução nas empresas de lapidação e verificar se os lapidadores obtêm o aproveitamento descrito no diagrama.

\section{Agradecimentos}

O projeto 3D-Gemas é financiado por meio da chamada pública MCT/Sebrae/Finep 07/2006 e foi oriundo de esforços de várias entidades, pesquisadores e empresários: Universidade de Passo Fundo (executora), Universidade Federal do Rio Grande do Sul (coexecutora), o Centro Tecnológico de Pedras, Gemas e Joias do Rio Grande do Sul e empresas intervenientes do Núcleo de Beneficiadores de Pedras, Gemas, Joias e Artesanato do projeto Sebrae-Empreender (2007). Este projeto também conta apoio do CNPq na forma de bolsas ITI-A e DTI-3.

\section{Referências}

[1] AEP SENAI SOLEDADE-RS, Sistema FIERGS. Apostila lapidação de gemas - processo manual, [s.n.t.], 2008.

[2] ASPAHAN, S. Manual de Lapidação. Como lapidar em máquinas Lapidart. Minas Gerais: Lapidart, 2006.

[3] HALL, C. Pedras Preciosas: um guia ilustrativo com mais 130 variedades de gemas. Rio de Janeiro: Ediouro, 1997.

[4] MARTINS, L. F.; MOL, A. A.; ROCHA, R. Desenvolvimento de ferramenta computacional para auxílio ao projeto de Gemas Lapidadas. Minas, 2005.

[5] RIBEIRO, A; PERES, M; IZIDORO, N. Leitura e interpretação de desenho técnico. Disponível em: $<$ http://www.faenquil.br/na_apostila/pdf/capitulo3.pdf $>$. Acesso em: jun. 2009.

[6] SCHULTZ, R. Gemas - flores do reino mineral. Disponível em: $<$ http://www.igc.usp.br/geologia/gemas.php>. Acesso em: jun. 2009.

[7] SCHUMANN, W. Gemas do mundo. 9. ed. Rio de Janeiro: Ao Livro Técnico, 2002.

\footnotetext{
${ }^{8}$ Refere-se às limitações físicas do processo manual e do processo mecanizado, pois esses processos não possuem suporte para uma medição tão exata (por exemplo: ângulo da coroa igual a $65,4321^{\circ}$, sendo substituído por $65,4^{\circ}$ neste caso).
} 